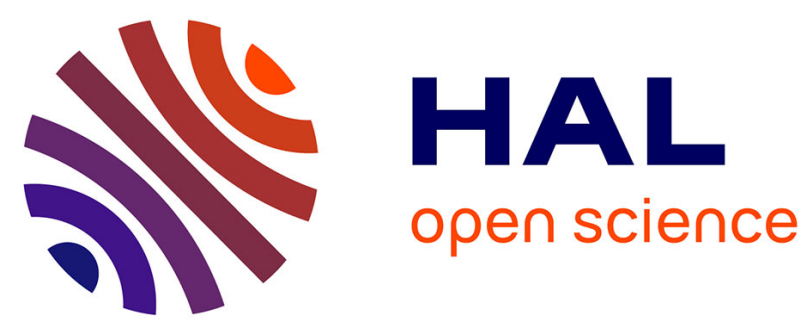

\title{
PYROLYTIC DECOMPOSITION OF SILANE ON LASER-IRRADIATED SILICA SUBSTRATES
}

\author{
D. Tonneau, Y. Pauleau, G. Auvert
}

\section{To cite this version:}

D. Tonneau, Y. Pauleau, G. Auvert. PYROLYTIC DECOMPOSITION OF SILANE ON LASERIRRADIATED SILICA SUBSTRATES. Journal de Physique Colloques, 1989, 50 (C5), pp.C5-637C5-645. 10.1051/jphyscol:1989574 . jpa-00229607

\section{HAL Id: jpa-00229607 https://hal.science/jpa-00229607}

Submitted on 1 Jan 1989

HAL is a multi-disciplinary open access archive for the deposit and dissemination of scientific research documents, whether they are published or not. The documents may come from teaching and research institutions in France or abroad, or from public or private research centers.
L'archive ouverte pluridisciplinaire HAL, est destinée au dépôt et à la diffusion de documents scientifiques de niveau recherche, publiés ou non, émanant des établissements d'enseignement et de recherche français ou étrangers, des laboratoires publics ou privés. 
PYROLYTIC DECOMPOSITION OF SILANE ON LASER-IRRADIATED SILICA SUBSTRATES

\author{
D. TONNEAU*, Y. PAULEAU and G. AUVERT \\ Centre National d'Etudes des Télécommunications, BP. 98, F-38243 \\ Meylan, France \\ " Société Bertin, BP. 22, F-13762, Les Milles, France
}

Résumé - Des microstructures ont été obtenues sur substrats de silice (recouverts ou non d'une couche mince de silicium) par décomposition du silane sous irradiation par un laser $\mathrm{CO}_{2}$ continu. La vitesse de dépôt des microstructures de silicium ayant un profil gaussien est proportionnelle à la pression de silane et varie linéairement avec la puissance du laser ou la température de la surface du substrat. A faible pression de silane (inférieure à $I$ Torr) et au-dessus de $1050^{\circ} \mathrm{C}$, des microstructures en forme d'anneau ont été déposées sur substrat de silice et la silice était gravée au centre du spot. Les mécanismes réactionnels intervenant dans le dépôt de silicium et la gravure de la silice sont analysés dans cet article.

Abstract - Microstructures were produced on Si-coated or uncoated silica substrates via $\mathrm{CW} \mathrm{CO}_{2}$ laser-induced decomposition of silane. The deposition rate of $\mathrm{Si}$ dots having a Gaussian profile was found to be proportional to the $\mathrm{SiH}_{4}$ pressure and linearly dependent on the laser power or laser-induced surface temperature. At low $\mathrm{SiH}_{4}$ pressures (below 1 Torr) and above $1050^{\circ} \mathrm{C}$, ring-shaped Si dots were deposited on silica substrates and $\mathrm{SiO}_{2}$ was etched at the center of the laser spot. The reaction mechanisms of the deposition of silicon and etching of silica are discussed in this paper.

\title{
1 - INTRODUCTION
}

Laser-induced chemical vapor deposition (LCVD) of doped-Si microstructures appears to be of great interest for the rewiring of prototype integrated circuits / $1 /$ and for various ather device applications such as discretionary changes, repairs or custom processing / $/ 2,3 /$. Pyrolytic decomposition of silane irradiated with a laser beam inducing a Gaussian temperature distribution on the substrate surface appears a promising process for fabrication of micron size polycrystalline Si lines. Since this decomposition rate depends exponentially on the reciprocal absolute temperature (Arrhenius law), the linewidth is expected to be significantly narrower than the laser beam diameter. The light emitted by a $\mathrm{cw} \mathrm{CO}_{2}$ laser tuned at $10.59 \mu \mathrm{m}$ is strongly absorbed by $\mathrm{SiH}_{4}$ molecules and $\mathrm{SiO}_{2}$ substrates. Using this type of laser beam, the deposition of silicon can occur via pyrolytic decomposition of vibrationally excited $\mathrm{SiH}_{4}$ molecules or silicon bearing species. As a result, the deposition rate of $S i$ films produced from these excited species is expected to be higher than the deposition rate of filims resulting from the thermally-activated pyrolysis of silane in furnace-type CVD reactors.

The purpose of our study is to investigate the deposition kinetics of Si microstructures on Si-coated or uncoated silica substrates locally heated with a focused $\mathrm{cW} \mathrm{CO}_{2}$ laser beam, and to elucidate the reaction mechanisms involved in the decomposition of silane. In a series of experiments, the thickness and deposition rate of $\mathrm{Si}$ microstructures produced on Si-coated silica substrates were determined as functions of the irradiation time, laser power and silane pressure. In another series of experiments carried out at lower silane pressures ( $f r o m$ ( 0.1 to 0.7 Torr), ring-shaped microstructures were deposited directly onto silica substrates and at the center of the laser spot, $\mathrm{SiO}_{2}$ was etched. The etching rate was measured as a function of the silane pressure and laser power. The reaction mechanisms involved in the decomposition of silane on the two types of substrates are discussed.

\section{2 - EXPERIMENTAL PROCEDURE}

The experimental set-up is represented schematically in Fig.l. After pumping down to about $1 \times$ $10^{-3}$ Torr, the reaction chamber was filled with pure silane. The reactant pressure measured with a capacitance gauge was varied from 0.1 to 15 Torr. The $\mathrm{cw} \mathrm{CO}_{2}$ laser was tuned at $10.59 \mu \mathrm{m}$ $\left(\mathrm{P}(20) \quad \mathrm{CO}_{2}\right.$ laser line). The laser beam penetrated into the deposition chamber through a transparent $\mathrm{NaCl}$ window and was focused on the substrate using a $25 \mathrm{~cm}$ focal length ZnSe lens. Silica plates of $l \mathrm{~mm}$ in thickness and Si-coated silica plates were used as substrates. The laser spot was maintained in a fixed position for a given irradiation time ( 1 to 15 s) determined by switching on and off the laser beam with a mechanical shutter. The spot diameter on the substrate surface of about $300 \mu \mathrm{m}$ at half intensity was determined experimentally $/ 4 /$. 
As a result, the microstructures formed in the hot spot were large enough for characterization by profilometer measurements.

The laser irradiation of substrates was carried out in a static atmosphere at a constant $\mathrm{SiH}_{4}$ pressure. The laser spot was moved on the substrate surface between each irradiation experiment using deflecting mirrors. The output laser power, mechanical shutter and deflecting mirrors were monitored by a computer. A series of experiments on a given substrate could be performed with a fixed $\mathrm{SiH}_{4}$ pressure at different output laser powers and irradiation times.

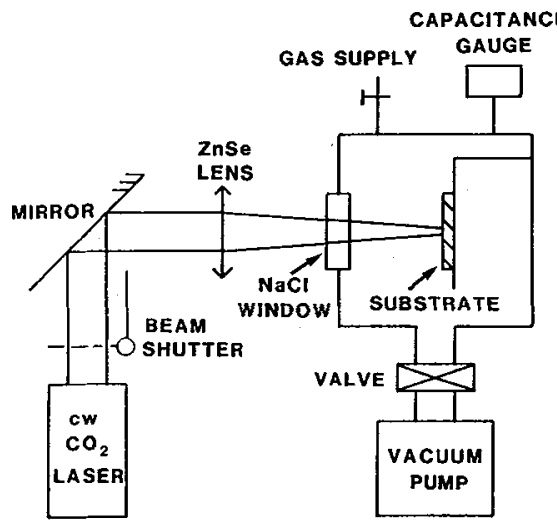

Fig.1 - Experimental arrangement.

Since the laser-induced temperature on the substrate surface was expected to be a dominant factor in the decomposition kinetics of silane, the temperature distribution on the substrate surface in the laser spot area was estimated by solving the heat-diffusion equation using the finite element method /5,6/. With the experimental configuration used, the laser-induced surface temperature, $T_{s}$, was found to be proportional to the laser power, $P_{t}$, on the substrate surface. In fact, with $\mathrm{SiH}_{4}$ molecules absorbing the laser light, the value of $P_{L}$ was less than the output laser power; $P_{0}$. The attenuation of the laser power and the actual laser power, $P_{1}$, on the substrate surface under given experimental conditions $\left(\mathrm{SiH}_{4}\right.$ presure, optical path length, laser spot diameter on the substrate,...) were deduced from measurements of the output laser powers required for melting the $S i$ coating on silica substrates (melting point of $S i=$ $1410^{\circ} \mathrm{C}$ ) under vacuum and at a given $\mathrm{SiH}_{4}$ pressure. The actual laser power, $P_{L}$, and laser-induced temperature, $T_{S}$, on the substrate surface at a given output laser power and $\mathrm{SiH}_{4}$ pressure were determined from these measurements and calculations.

\section{3 - RESULTS AND DISCUSSION}

3 - 1 - Decomposition of silane on Si-coated silica substrates

Since the laser beam was maintained in a fixed position during the laser irradiation, the decomposition of silane led to the formation of dot-shaped polycrystalline Si microstructures. The decomposition kinetics of silane was determined from the profilometer measurements of the height of these dots. Silicon dots having a Gaussian profile were produced at various $\mathrm{SiH}_{4}$ pressures and output laser powers. The height of these Gaussian Si dots was proportional to the irradiation time (figs.2 and 3). As the deposition rate of these dots exibited no dependence on changes in irradiation time, the deposition process occurred at a quasi-steady state, in particular at a constant temperature for irradiation times longer than 1 s. This experimental result is in good agreement with the temperature dependence on irradiation time predicted by the theoretical calculation $/ 5,6 /$. The data presented in $\mathrm{Fig.2}$ show that the effect of $\mathrm{SiH}_{4}$ pressure on the deposition rate at a given output laser power $(0.8 \mathrm{~W})$ is slightly complex. An increase in $\mathrm{SiH}_{4}$ pressure led simultaneously to an increase in deposition rate and a decrease in laser power, $P_{L}$, on the substrate surface. At $0.8 \mathrm{~W}$, the deposition rate was unchanged by varying $\mathrm{SiH}_{4}$ pressure from 5 to 6 Torr since the effects of pressure and temperature on the deposition rate were probably equivalent. The deposition rate of Gaussian Si dots increased with increasing output laser power (Fig.3). In other words, the deposition rate was dependent on the laser-induced temperature of the substrate surface.

The dependence of the height of $\mathrm{Si}$ microstructures on the laser power is illustrated in Fig.4. At a given $\mathrm{SiH}_{4}$ pressure, three stages could be distinguished in the process depending upon the laser power value. Below $0.68 \mathrm{~W}$, no deposition occurred whatever the $\mathrm{SiH}_{4}$ pressure. At laser powers higher than this threshold value, Gaussian Si dots were produced and the height of these dots increased linearly with increasing laser power or laser-induced temperature of substrates. 


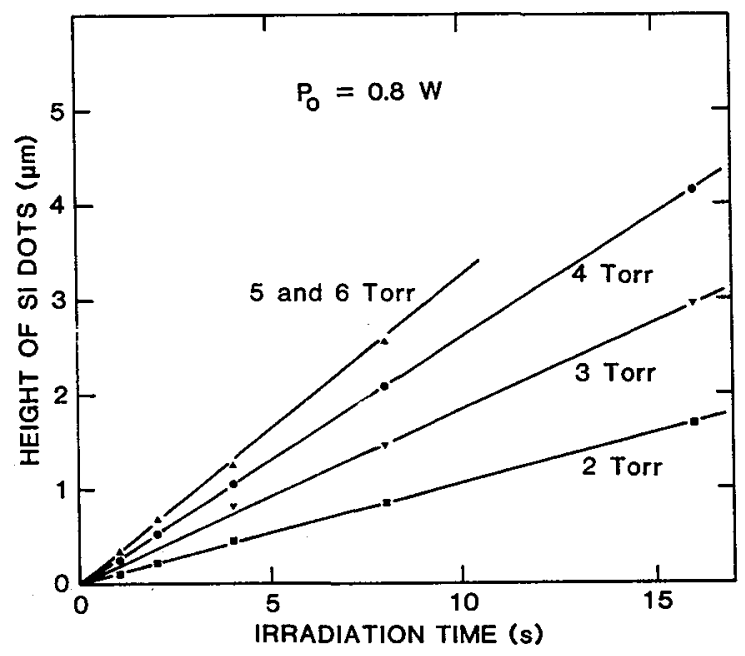

Fig.2 - Height of Gaussian Si dots versus irradiation time - $\mathrm{SiH}_{4}$ pressure effect.

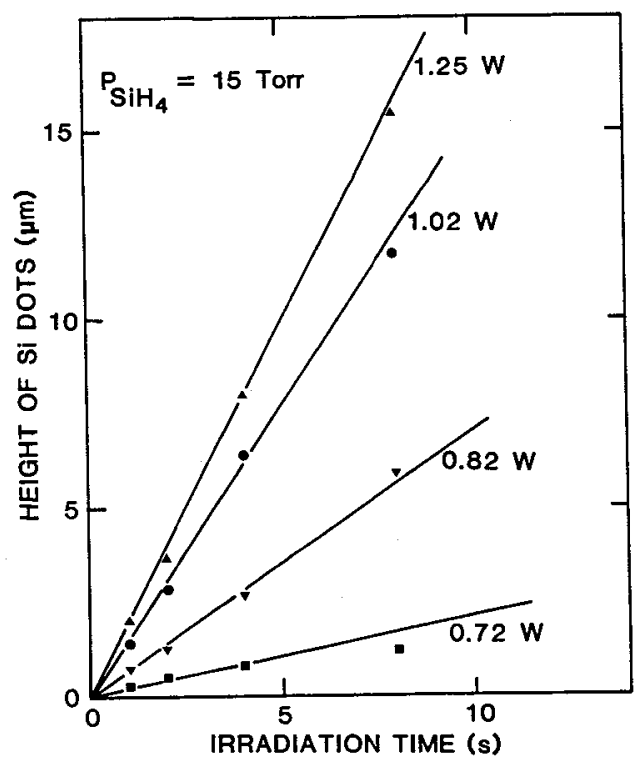

Fig.3 - Height of Gaussian Si dots versus irradiation time - output laser power effect.

Above $1.13 \mathrm{~W}$, volcano-shaped $\mathrm{Si}$ dots were deposited. This threshold value of $1.13 \mathrm{~W}$ was the laser power, $P_{L}^{m}$, required on the substrate surface for $S i$ melting at the center of the laser spot. The volcano shape resulted from the attack of $\mathrm{SiO}_{2}$ by silicon. The $\mathrm{SiO}_{2}$ etching was revealed by small pits in silica substrates observable by optical microscopy after Si stripping. At high temperatures $\left(T_{s}>1410^{\circ} \mathrm{C}\right)$, silicon monoxide, Sio, formed by interaction between $\mathrm{Si}$ and $\mathrm{SiO}_{2}$, diffused in liquid $\mathrm{Si}$ and was vaporized. The maximum height of these volcano-shaped $\mathrm{Si}$ dots (or height of the craters) was independent of laser power. At the rim of the craters, the deposition temperature was constant $\left(1410^{\circ} \mathrm{C}\right)$ since the solid-liquid equilibrium was established. Although $\mathrm{SiH}_{4}$ molecules or other reactive species absorb the laser light, the independence of the deposition rate on the laser power at a constant temperature suggests that the photolytic effect on the deposition process is negligible. As a result, the deposition temperature appears to be the major parameter governing the kinetics of the $\mathrm{cw} \mathrm{CO}_{2}$ laser-induced decomposition of silane. 


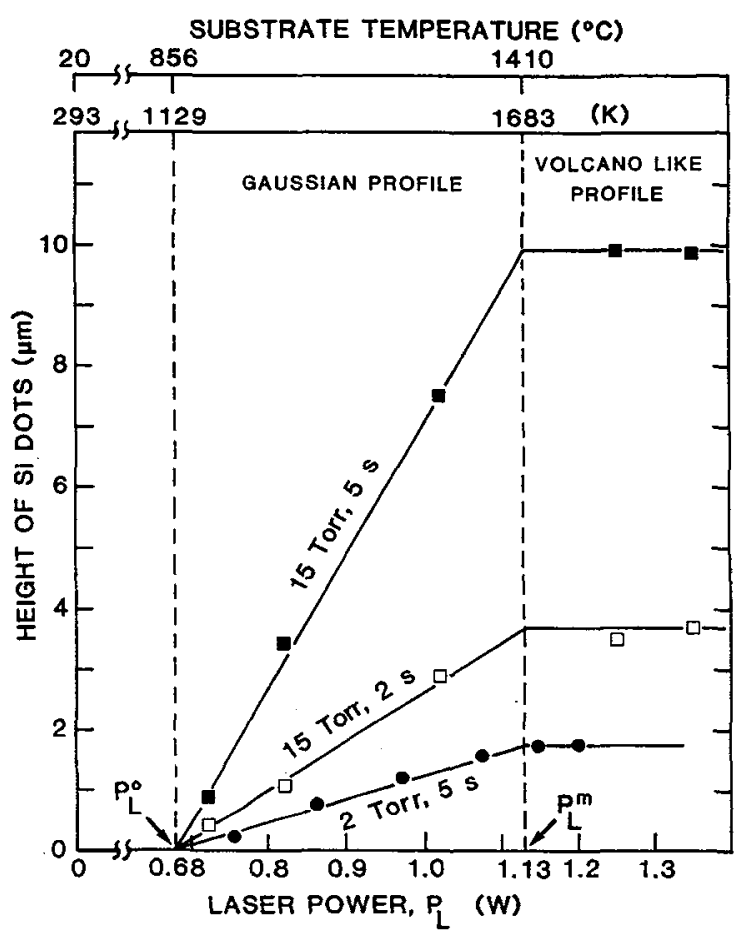

Fig.4 - Height of $S i$ dots versus laser power, $P_{L}$, available on the substrate surface for various $\mathrm{SiH}_{4}$ pressures and irradiation times.

The deposition rate of Gaussian $\mathrm{Si}$ dots produced at $1410^{\circ} \mathrm{C}$ or at lower temperatures was found to be proportional to the $\mathrm{SiH}_{4}$ pressure (Fig.5). The relationship between the deposition rate of these dots and the laser power, $P_{L}$, is given by the following equation :

$$
D_{R}=k_{R} P_{S i H 4}\left(P_{L}-P_{L}^{a}\right)
$$

where $k_{R}$ is the rate constant, $P_{S i H 4}$ the $S_{i H}$ pressure and $P_{L}{ }^{0}$ the laser power threshold for the onset of the deposition of silicon (under our experimental conditions, $P_{L}{ }^{0}=0.68 \mathrm{~W}$ ).

The substrate temperature at the center of the laser spot for the onset of the deposition of silicon was $856^{\circ} \mathrm{C}$. This value is considerably higher than the temperature of $500^{\circ}-550^{\circ} \mathrm{C}$ required for the deposition of $\mathrm{Si}$ films by pyrolysis of silane in hot wall or cold wall low pressure CVD reactors. The deposition rate dependence on laser-induced temperature is presented in the Arrhenius diagram given in $\mathrm{Fig.6}$. The $\mathrm{CW} \mathrm{CO}_{2}$ laser-induced decomposition of silane clearly does not comply with the Arrhenius law. On the other hand, using the $\mathrm{CO}_{2}$ laser irradiation, the deposition of $\mathrm{Si}$ dots starts at a laser threshold of $0.68 \mathrm{~W}_{\text {whatever }}$ the $\mathrm{SiH}_{4}$ pressure. These results are quite different from those reported for the $\mathrm{CW} \mathrm{Ar}^{+}$laser-induced deposition of $S i$ rods $v i a$ pyrolysis of silane $/ 7,8 /$. In this latter case, an exponential increase in deposition rate with increasing laser-induced temperature from $900^{\circ}$ to $1130^{\circ} \mathrm{C}$ was observed and the activation energy deduced from the Arrhenius law was $44.3 \pm 4 \mathrm{kcal}^{\mathrm{mol}} \mathrm{l}^{-1}$. This value is relatively close to the activation energy of $37.4 \mathrm{kal}^{-1}$ reported for the deposition of $\mathrm{Si}$ films by pyralysis of silane between $560^{\circ}$ and $780^{\circ} \mathrm{C}$ in a cold wall low pressure CVD reactor $/ 9 /$.

The reaction mechanism for the deposition of silicon via pyrolysis of silane either in hot wall $/ 10,11 /$ or cold wall /12,13/ conventional CVD reactors is complex and not fully understood. At low temperatures, the deposition rate of $\mathrm{Si}$ films and the decomposition of silane are controlled by a surface reaction whereas above a certain temperature, the kinetics of the decomposition process becomes mass-transport limited and the deposition rate is less dependent on the deposition temperature. These major characteristics have been obtained for the $\mathrm{cw} \mathrm{Ar}^{+}$ laser-induced decomposition of silane. However, compared with a decomposition process carried out in a furnace-type CVD reactor, the laser-induced deposition process led to much higher deposition rates (by a factor of $10^{2}-10^{3}$ ) at a given deposition temperature since the deposition process was performed at higher $\mathrm{SiH}_{4}$ pressures without the detrimental formation of 


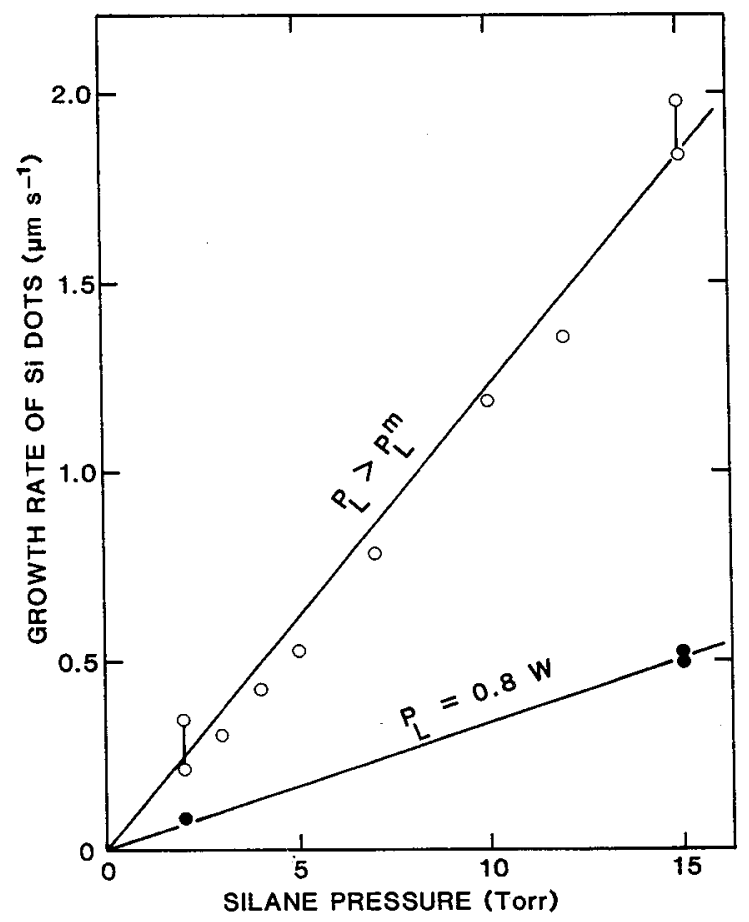

Fig. 5 - Deposition rate of Gaussian Si dots versus $\mathrm{SiH}_{4}$ pressure.

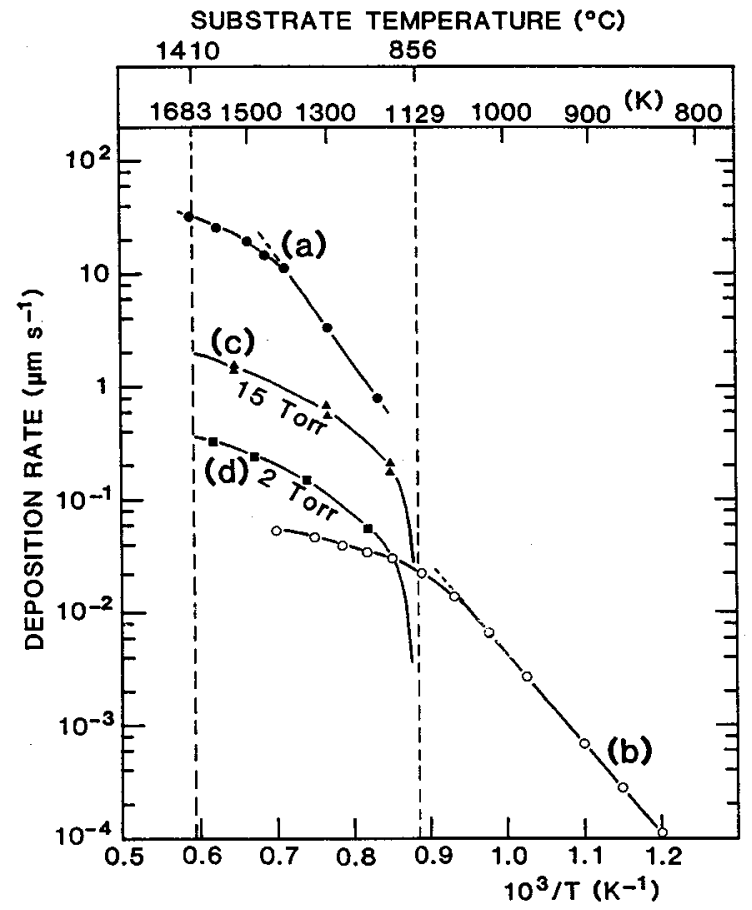

Fig.6 - Arrhenius diagram - (a) $\mathrm{CW} \mathrm{Ar}+$ LCVD of Si rods, $\mathrm{SiH}_{4}$ pressure of 100 Torr (from /7,8/); (b) CVD of $\mathrm{Si}$ films in a cold wall CVD reactors, $\mathrm{SiH}_{4}$ pressure of 0.76 Torr and $\mathrm{N}_{2}$ or $\mathrm{Ar}$ pressure of $6.84 \operatorname{Torr}$ (from /9/); (c and d) $\mathrm{CW} \mathrm{CO}_{2} \mathrm{LCVD}$ of $\mathrm{Si}_{i}$ dots. 
powdery $\mathrm{Si}$ by gas phase nucleation; in addition, the kinetics of the LCVD process was surface reaction controlled at much higher deposition temperatures. These distinctive features of the LCVD process have been analyzed as a consequence of the strong localization of the laser heating process $/ 8 /$.

The kinetics data of the $\mathrm{cw} \mathrm{CO}_{2}$ laser-induced decomposition of silane are quite different from those obtained with a $\mathrm{cw} \mathrm{Ar}{ }^{+}$laser or with a furnace-type CVD reactor. The classical reaction mechanisms proposed for the pyrolysis of silane cannot be invoked; in particular, the decomposition of silane by a surface reaction in the adsorbed phase is no longer the rate-limiting step since the deposition rate of Gaussian Si dots does not fit the Arrhenius law. The $\mathrm{SiH}_{4}$ pressure effect on the deposition rate of $\mathrm{Si}$ dots suggests that the deposition kinetics may be limited by the number of collisions between $\mathrm{SiH}_{4}$ molecules and the silicon surface heated with the laser beam. The surface collision frequency, $Z$, per unit area is proportional to the gas pressure, $\mathrm{P}$ :

$$
Z=P N_{0} /(2 \pi M R T)^{1 / 2}
$$

where $N_{0}$ is the Avogadro number, $R$ the ideal gas constant, $M$ and $T$ the molar mass and absolute gas temperature, respectively.

Since the laser heating of substrates is strongly localized and the heat conductivity of substrates is higher than that of silane, the variation in the gas phase temperature with laser power may be negligible compared with that of the substrate temperature. The yield of the deposition process given by the ratio of the number of $\mathrm{SiH}_{4}$ molecules dissociated to the number of $\mathrm{SiH}_{4}$ molecules impinging on the substrate is $0.2 \%$ for a deposition rate of $2 \mu \mathrm{m} \mathrm{s}^{-1}$ at $1410^{\circ} \mathrm{C}$ with 15 Torr of silane. Consequently, any depletion phenomena can be excluded and no rate limiting step such as a gas phase diffusion process can be invoked.

The substrate temperature for the onset of the laser-induced deposition of silicon estimated to be $856^{\circ} \mathrm{C}$ is significantly higher than the temperature required for deposition of $S i$ in a furnace-type CVD reactor. The deviation in deposition temperature may result from a difference in the excitation level of molecules and reactant species. Using a furnace-type reactor, the volume of reactant gas heated at a temperature close to the substrate temperature is relatively large and reactant precursors such as $\mathrm{SiH}_{2}$ or $\mathrm{SiH}_{3}$ radicals may be created in the gas phase; these gaseous precursors can decompose and provide $\mathrm{Si}$ films at much lower temperatures than that required in the laser-induced deposition process. The exiatence of the temperature threshold $\left(856^{\circ} \mathrm{C}\right)$ suggests that $\mathrm{SiH}_{4}$ molecules gain the vibrational energy for their dissociation during collisions with the $S i$ surface in the hot spot. Above the temperature threshold, the energy balance at the substrate surface would be favorable to the dissociation of $\mathrm{SiH}_{4}$ molecules. The vibrational energy of the $\mathrm{Si}$ lattice being proportional to the substrate temperature, the number of $\mathrm{SiH}_{4}$ molecules able to reach the energy level required for dissociation is expected to be linearly dependent on the substrate temperature. Assuming this mechanism, the deposition rate of Gaussian $\mathrm{Si}$ dots proportional to the number of $\mathrm{SiH}_{4}$ molecules impinging on the substrate surface is also linearly dependent on the substrate temperature above $856^{\circ} \mathrm{C}$. This deposition rate dependence on the substrate temperature is in concordance with the kinetic data.

The effect of photons on the decomposition of silane can be disregarded for several reasons. The photodecomposition of molecules would induce the formation of powdery $S i$ by volume reactions. These volume reactions are known to lead to a depletion of reactive gas in the vicinity of substrates and the deposition rate would decrease considerably with increasing gas pressure. Actually, the formation of powdery $\mathrm{Si}$ by homogeneous decomposition of sjlane cquld be performed with a pulsed $\mathrm{CO}_{2}$ laser operating at a power density in the range of $10^{7} \mathrm{~W} \mathrm{~cm}^{-2} / 14 \zeta$, i.e., considerably higher than the power density of the $\mathrm{cw} \mathrm{CO}_{2}$ laser which was about $1.5 \times 10^{3}$ $W \mathrm{~cm}^{-2}$. In addition, the deposition rate of volcano-shaped $\mathrm{Si}$ dots at $1410^{\circ} \mathrm{C}$ being independent of laser power, the photodecomposition of $\mathrm{SiH}_{4}$ molecules must be excluded from the deposition mechanism of $\mathrm{Si}$ dots produced by the $\mathrm{CO}_{2}$ laser-induced decomposition of silane on $\mathrm{S} i$-coated silica substrates.

\section{$3-2$ - Decomposition of silane on silica substrates}

At $\mathrm{SiH}_{4}$ pressures higher than typically 1 Torr, Gaussian $\mathrm{Si}$ dots were deposited on silica substrates irradiated with laser powers up to $2.5 \mathrm{~W}$. This deposition process is equivalent to the deposition process of $S i$ dats on Si-casted silica substrates. The situation was different at $\mathrm{SiH}_{4}$ pressures ranging from 0.1 to 1 Torr. The typical profiles of microstructures produced at a $\mathrm{SiH}_{4}$ pressure of 0.5 Torr for an irradiation time of $2 \mathrm{~s}$ are presented in Fig.7. Gaussian Si dots were deposited at a laser power of $1.2 \mathrm{~W}$. Ring-shaped Si microstructures were produced at $1.4 \mathrm{~W}$ corresponding to a laser-induced surface temperature of about $950^{\circ} \mathrm{C}$. At higher laser powers, the silica substrate was etched at the center of the ring-shaped microstructure. The deposition rate of Gaussian $\mathrm{Si}$ dots as well as the etching rate of $\mathrm{SiO}_{2}$ substrates at the center of the laser spot were determined as functions of the $\mathrm{SiH}_{4}$ pressure at output laser 
powers inducing substrate temperature of about $1400^{\circ} \mathrm{C}$ (Fig.8). Above 0.7 Torr, Gaussian Si dots were produced with a deposition rate proportional to the $\mathrm{SiH}_{4}$ pressure. The constant rate of $0.11 \mathrm{\mu m} \mathrm{s} \mathrm{s}^{-1} \operatorname{Torr}^{-1}$ for the deposition at $1400^{\circ} \mathrm{C}$ is equivalent to that obtained for the deposition of $\mathrm{Si}$ dots on Si-coated silica substrates. The part of the curve in dotted line (Fig.8) represents the deposition rate of $S i$ dots on inert substrates (for example, on $\mathrm{Si}$-coated silica substrates). In fact, this curve gives the decomposition rate of silane on $\mathrm{Si}$ substrates. Below 0.7 Torr, the $\mathrm{SiO}_{2}$ substrate was etched and this reaction rate was also

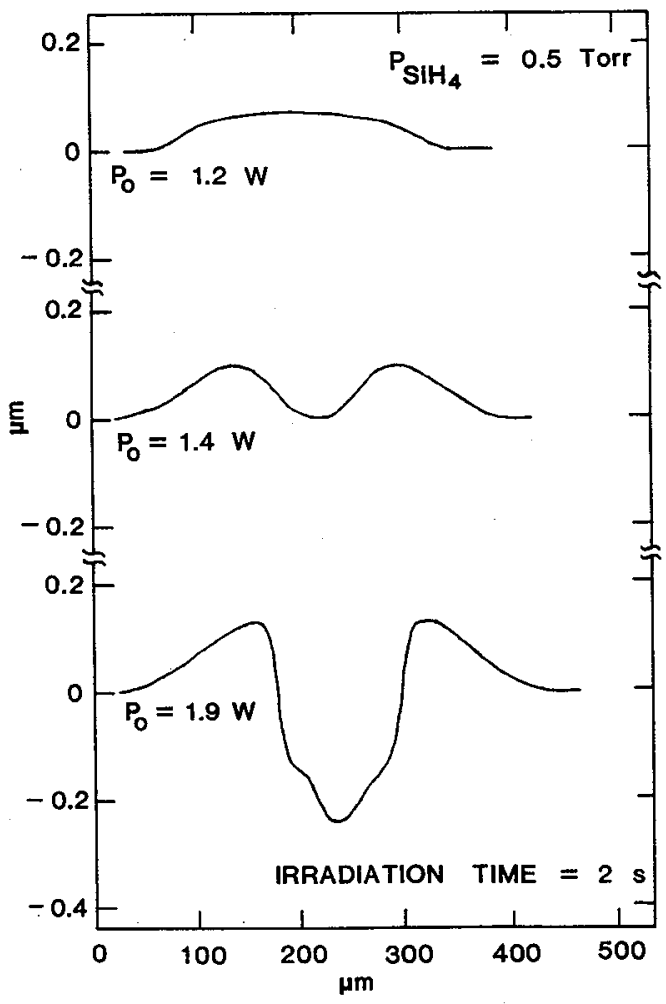

Fig.7 - Typical profiles of microstructures obtained on silica substrates.

proportional to the $\mathrm{SiH}_{4}$ pressure. The reaction rates for the deposition and etching processes can be expressed in $S i$ atoms $\mathrm{cm}^{-2} \mathrm{~s}^{-1}$ considering the $\mathrm{Si}$ atom density of $5 \times 10^{22}$ and $2.2 \times$ $10^{22}$ at $/ \mathrm{cm}^{3}$ in $\mathrm{Si}$ and $\mathrm{SiO}_{2}$, respectively ( $\mathrm{Fig.8}$ ). The data points (closed square symbols) corresponding to the etching of $\mathrm{SiO}_{2}$ are located on the curve in dotted line. Consequently, the etching rate of $\mathrm{SiO}_{2}$ is the same as the deposition rate of silicon on inert substrates which is, in fact, the decomposition rate of $\mathrm{SiH}_{4}$ molecules.

The dependence of the etching rate of $\mathrm{SiO}_{2}$ on the laser power is demonstrated in $\mathrm{Fig} .9$ at $\mathrm{SiH} 4$ pressures of 0.5 and 0.7 Torr. The etching rate increases linearly with increasing laser power or substrate temperature up to $1410^{\circ} \mathrm{C}$. In other words, the kinetics of the etching process does not comply with the Arrhenius law. The substrate temperature corresponding to an etching rate of zero is found to be $1050^{\circ} \mathrm{C}$ by extrapolating the curves given in Fig.9. This temperature is independent of $\mathrm{SiH}_{4}$ pressure.

The $\mathrm{cw} \mathrm{CO}_{2}$ laser-induced decomposition of silane on silica substrates has led to the formation of Gaussian $\mathrm{Si}$ microstructures at surface temperatures lower than $950^{\circ} \mathrm{C}$. For laser-induced surface temperatures in the range of $950^{\circ}$ to $1050^{\circ} \mathrm{C}$, the formation of ring-shaped Si microstructures may result from the high surface mobility of $\mathrm{Si}$ atoms on silica substrates at the center of the laser spot. The Si atoms produced at the center of the irradiated zone could migrate towards the outer part of the laser spot, i.e., towards a region at a lower temperature. The migration phenomenon was observed only at low $\mathrm{SiH}_{4}$ pressures (below 1 Torr). With a laser-induced temperature higher than $1050^{\circ} \mathrm{C}$ at the center of the irradiated zone, SiH molecules were decomposed at the periphery of the heated zone and ring-shaped Si deposits were produced. At the center of the laser spot, the Si atoms produced via pyrolysis of silane were probably converted into $\mathrm{SiO}$ vapor by reaction of $\mathrm{Si}$ with $\mathrm{SiO}_{2}$. Indeed, the onset of the $\mathrm{SiO}$ 


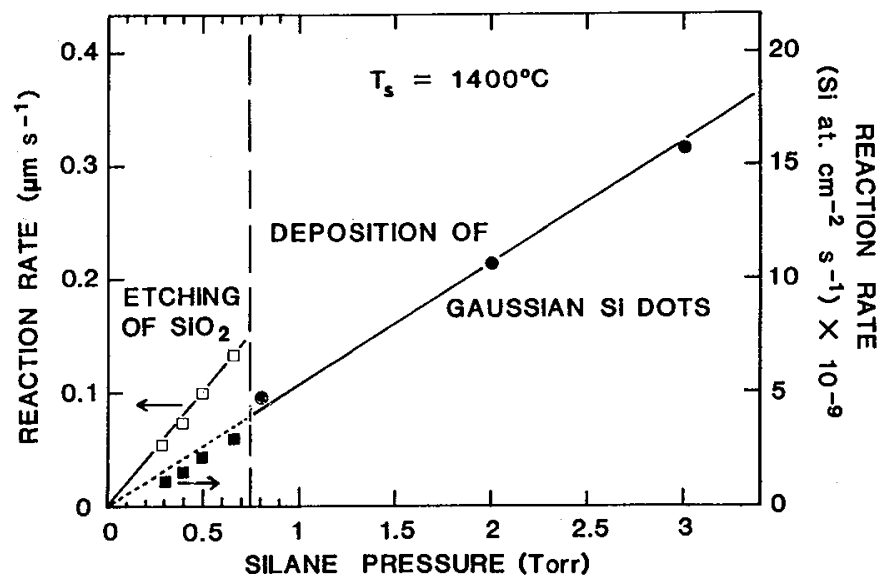

Fig. 8 - Deposition rate of Gaussian $\mathrm{Si}$ dots and etching rate of $\mathrm{SiO}_{2}$ versus $\mathrm{SiH}_{4} \mathrm{pressure.}$

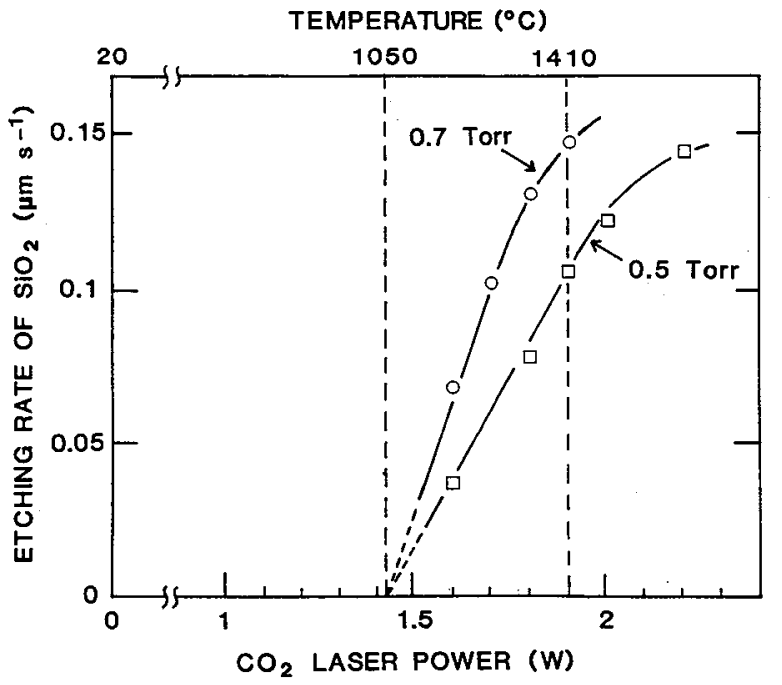

Fig.9 - Etching rate of $\mathrm{SiO}_{2}$ versus laser power, $\mathrm{P}_{\mathrm{L}}$, on the substrate surface.

sublimation from $\mathrm{Si}-\mathrm{SiO}_{2}$ mixtures has been demonstrated to occur at $1050^{\circ} \mathrm{C} / 15 /$. The nucleation and growth of $\mathrm{Si}$ films via pyrolysis of silane in furnace-type CVD reactors has been thoroughly investigated $/ 9,16,17 /$. The saturation density of $\mathrm{Si}$ clusters between $925^{\circ}$ and $1200^{\circ} \mathrm{C}$ was found to decrease more rapidly on silica substrates than silicon nitride substrates. This difference was explained by the reaction between $\mathrm{Si}$ atoms and $\mathrm{SiO}_{2}$ resulting in volatile $\mathrm{SiO}$, whereas the thermodynamically unfavarable reaction between $5 i$ and $\mathrm{Si}_{3} \mathrm{~N}_{4}$ could bo disregarded. In addition, the surface of silica substrates observed by scanning electron microscopy was partially deteriorated probably due to the formation of $5 i 0$ when relatively low input concentrations (or partial pressures) of silane were used for CVD of $\mathrm{Si}$ films above $1100^{\circ} \mathrm{C} / 9 /$. The etching kinetics of silica substrates via laser-induced decomposition of silane was governed by the decomposition kinetics of silane since the etching rate dependence and the deposition rate dependence on the $\mathrm{SiH}_{4}$ pressure and substrate temperature were similar.

\section{4 - CONCLUSION}

The $\mathrm{CW} \mathrm{CO}_{2}$ laser-induced decomposition of silane on Si-coated or uncoated silica substrates can provide $\mathrm{Si}$ microstructures with relatively high deposition rates (up to $1 \mu \mathrm{m} \mathrm{s}^{-1}$ ); the deposition rate was found to be proportional to the $\mathrm{SiH}_{4}$ pressure and linearly dependent on the 
laser power or substrate temperature. The reaction mechanism proposed for pyrolysis of silane in furnace-type CVD reactors cannot be invoked to explain the experimental results of our kinetic study. The deposition rate was found to be proportional to the number of collisions between $\mathrm{SiH}_{4}$ molecules and the substrate surface. Although $\mathrm{SiH}_{4}$ molecules absorb the laser

light, the contribution of a photolytic decomposition of silane to the deposition process was observed to be negligible. At low $\mathrm{SiH}_{4}$ pressures (below 1 Torr) and above $1050^{\circ} \mathrm{C}$, the interaction between $\mathrm{SiO}_{2}$ and $\mathrm{Si}$ atoms produced by the decomposition of silane led to the volatilization of $\mathrm{SiO}$ and resulted in the $\mathrm{SiO}_{2}$ etching at the center of the irradiated zone. The kinetics of this etching process was totally dominated by the decomposition kinetics of $\mathrm{SiH}_{4}$ molecules.

\section{REFERENCES}

/1/ Singer, P.H., Semiconductor International, August (1986) 30.

/2/ Dsgood, R.M., Jr., Ann. Rev. Phys. Chem., 34 (1983) 77.

/3/ Osgood, R.M., Jr., Ehrlich, D.J., Deutsch, T.F., Silversmith, D.J. and Sanchez, A., in "Laser Processing of Semiconductor Devices", Proceedings of SPIE, edited by Tang, C.C., Vol.385, (The International Society for Optical Engineering, Bellingham, WA, 1983), p.120.

14/ Tonneau D., PhD Thesis, Université Joseph Fourier, Grenoble, France, (1988).

15/ Tonneau, D. and Auvert, G., in "Photon, Beam and Plasma-Enhanced Processing", Proceedings of the European Conference of the Materials Research Society, edited by Golanski, A., N'Guyen, V.T. and Krimmel, E.F., Vol.XV, (Editions de Physique, Paris, 1987), P.169.

16/ Tonneau, D. and Auvert, G., in "Laser and Particle-Beam Chemical Processing for Microelectronics", Mat. Res. Soc. Symp. Proc., edited by Ehrlich, D.J., Higashi, G.S. and Oprysko, M.M., Vol.101, (Materials Research Society, Pittsburgh, PA, 1988), p.131.

17/ Bäuerle, D., Irsigler, P., Leyendecker, G., Noll, H. and Wagner, D., Appl. Phys. Lett., 40 (1982) 819.

/8/ Bäuerle, D., Proceedings of the International Conference on Surface Studies with Lasers, edited by Aussenegg, F., Leitner, A. and Lippitsch, M.E., Springer Series on Chemical Physics, Vol.33, (Springer-Verlag, Heidelberg, 1983), p.178.

19/ Claassen, W.A.P. and Bloem, J., in "Semiconductor Silicon 1981", Proceedings of the International Symposium on Silicon Material Science and Technology, edited by Huff, H.R., Kriegler, R.J. and Takeishi, Y., Vol.81-5, (Electrochemical Society, Pennington, NJ, 1981), p. 365 .

$110 /$ van den Brekel, C.H.J. and Bollen, L.J.M., J. Cryst. Growth, 54 (1981) 310.

l11/ Claassen, H.A.P., Bloem, J., Valkenburg, G.J.N. and van den Brekel, C.H.J., J. Cryst. Growth, 57 (1983) 259.

112/ Cadoret, R. and Hottier, F., J. Cryst. Growth, 61 (1983) 259.

113/ Cadoret, R. and Hottier, F., J. Cryst. Growth, 64 (1983) 583.

14/ Pauleau, Y., Tonneau, D. and Auvert, G., in "Laser Processing and Diagnostics, Applications in Electronic Materials", edited by Baüerle, D., Chemical Physics Serie, Vol.39, (Springer-Verlag, Heidelberg, 1984), p.215.

115/ Collignon, J.-C., Ph.D Thesis, N0521, University of Lyon, France, (1968).

16/ Bloem, J., in "Chemical Vapor Deposition 1979", Proceedings of the 7th International Conference on CVD, edited by Sedwick, T.O. and Lydtin, H., (Electrochemical Society, Pennington, NJ, 1979), p.41.

$/ 17 /$ Claassen, W.A.P. and Bloem, J., J. Electrochem. Soc., 127 (1980) 194. 